\title{
Filtração de aerossóis em altas temperaturas utilizando filtros cerâmicos de dupla camada: influência do diâmetro de partícula na eficiência de coleta
}

\section{(Filtration of aerosols at high temperatures using a double layer ceramic filter: influence of the particle diameter in the collection efficiency)}

\author{
N. L de Freitas, M. G. Maniero, J. R. Coury \\ Departamento de Engenharia Química - DEQ \\ Universidade Federal de S. Carlos - UFSCar \\ Rod. Washington Luiz, km 235, C. P. 676, S. Carlos, SP 13565-905 \\ jcoury@power.ufscar.br
}

\begin{abstract}
Resumo
Neste trabalho foram utilizados filtros cerâmicos para filtração de aerossóis, constituídos por dupla camada, onde a primeira camada é formada por um suporte celular de elevada porosidade com diâmetro de poro controlado e a segunda formada por uma película filtrante. A camada suporte foi obtida pela técnica de replicação cerâmica de espuma poliuretânica, por meio da impregnação de uma suspensão aquosa de $\mathrm{Al}_{2} \mathrm{O}_{3}$. Foram utilizados suportes de 45 e 75 poros/polegada. A membrana filtrante $\left(\mathrm{Al}_{2} \mathrm{O}_{3}\right.$ e argila) foi a mesma para ambos os suportes, sendo composta por uma massa granular cerâmica de baixa porosidade. Os experimentos de filtração foram realizados em temperaturas de 25 a $700{ }^{\circ} \mathrm{C}$ onde mediu-se a capacidade dos filtros de limpar um aerossol de partículas finas polidispersas (diâmetro mediano de $4,6 \mu \mathrm{m}$ ) e calculou-se a eficiência de coleta para diâmetros de partícula entre 0,4 e 8,5 $\mu \mathrm{m}$. Os resultados mostraram que a eficiência diminuiu com o aumento da temperatura e aumentou com o diâmetro da partícula.

Palavras-chave: filtração, filtro cerâmico, eficiência de coleta, aerossol.
\end{abstract}

\begin{abstract}
In this work, ceramic filters were used for aerosol filtration. The filters were constituted by two layers, where the first layer was formed by of a highly porous ceramic support with controlled pore size and the second layer constituted by a fine membrane. The ceramic support was obtained from polymeric foams utilizing a technique of alumina impregnation. The supports had 45 and 75 pores per inch (ppi). The membrane (a mixture of alumina and clay) was the same for the two supports, with much smaller pore sizes. The filtration experiments were accomplished at temperatures varying from 25 to $700{ }^{\circ} \mathrm{C}$, where the ability of the filters for cleaning an aerosol constituted by fine particles (median diameter of $4.6 \mu \mathrm{m}$ ) was measured. The collection efficiency was calculated for particle diameters between 0.4 and $8.5 \mu \mathrm{m}$. The results showed that the collection efficiency decreased with the increase of the temperature and increased with particle diameter.
\end{abstract}

Keywords: filtration, ceramic filters, collection efficiency, aerosol.

\section{INTRODUÇÃO}

A conscientização ambiental vem crescendo significativamente nos últimos anos. Os legisladores têm aumentado severamente o controle na emissão de particulados em vários processos e atividades.

Atualmente o interesse por filtros cerâmicos e granulares, tem aumentado significativamente sendo responsável por mais de $80 \%$ do espaço dedicado na literatura ao desenvolvimento de sistemas de limpeza de gases quentes [1-5]. As excelentes propriedades de filtração e o baixo custo de fabricação e manutenção tornaram os filtros cerâmicos a opção preferida na maioria das aplicações de limpeza [6-9].

$\mathrm{O}$ uso de filtros rígidos cerâmicos já provou ser uma das melhores tecnologias na filtração de partículas na faixa sub- micrométrica. As resistências térmica, química e mecânica, além da altíssima eficiência de coleta parecem ser insuperáveis por qualquer outro equipamento de limpeza operando ao mesmo custo.

Em trabalhos recentes [10-14], foram caracterizados e testados filtros cerâmicos de dupla camada que consistem de um suporte cerâmico com uma membrana depositada. A membrana filtrante apresenta tamanho de poros capaz de evitar a penetração do material particulado, podendo ser bastante fina para minimizar a queda de pressão. Por outro lado, o suporte deve possuir alta porosidade e resistência mecânica suficiente para suportar a membrana.

Este trabalho tem por objetivo estudar a influência do diâmetro de partícula na eficiência de coleta na filtração de aerossóis em temperaturas elevadas utilizando filtros cerâmicos de dupla camada. 


\section{MATERIAIS E MÉTODOS}

A preparação do filtro cerâmico de dupla camada foi realizada em duas etapas: a preparação do suporte e, posteriormente, a preparação da película filtrante que era depositada sobre o suporte.

O suporte foi preparado a partir de uma esponja de poliuretano com $97 \%$ de porosidade aparente e contagem de poros de 45 e 75 poros por polegada linear (ppi), utilizando a técnica de replicação polimérica [11-14].

A membrana cerâmica foi preparada por meio de uma pasta cerâmica a partir de $75 \%$ (em massa) de alumina eletrofundida (\#-70+80), 25\% de argila (\#-200), 0,20 mL de água destilada por $1 \mathrm{~g}$ de material sólido e silicato de sódio. Essa pasta foi depositada manualmente (com o auxílio de uma espátula) sobre o suporte cerâmico. Após secagem adequada, esta membrana foi consolidada ao suporte por uma queima prolongada a $1400{ }^{\circ} \mathrm{C}$ $[11,13,14]$.

Os filtros cerâmicos utilizados neste trabalho foram preparados em forma de discos com $6,6 \mathrm{~cm}$ de diâmetro e espessuras de 1,75 e $1,8 \mathrm{~cm}$ para os suportes porosos com contagem linear de poros por polegada (ppi) de 45 e 75, respectivamente, sendo a membrana filtrante de aproximadamente $1 \mathrm{~mm}$ de espessura [14].

Para os testes de filtração, o equipamento utilizado consistiu de uma linha de ar comprimido, o gerador de aerossol do tipo leito fluidizado (TSI-2300), um medidor de vazão (rotâmetro) e a câmara de ensaio, como mostra a Fig. 1.

O elemento filtrante foi inserido na câmara de ensaio que consistia de duas seções cilíndricas de aço refratário e adaptadas a um suporte fixo. O filtro foi colocado em um porta-amostras entre as seções cilíndricas que foram, posteriormente, vedadas.

$\mathrm{O}$ aquecimento do ar foi realizado na própria câmara de ensaios por meio de um forno acoplado a um controlador de temperatura do tipo PID. A temperatura foi medida por meio de dois termopares do tipo $\mathrm{K}$, que foram inseridos dentro do forno, sendo um abaixo e outro acima da amostra.

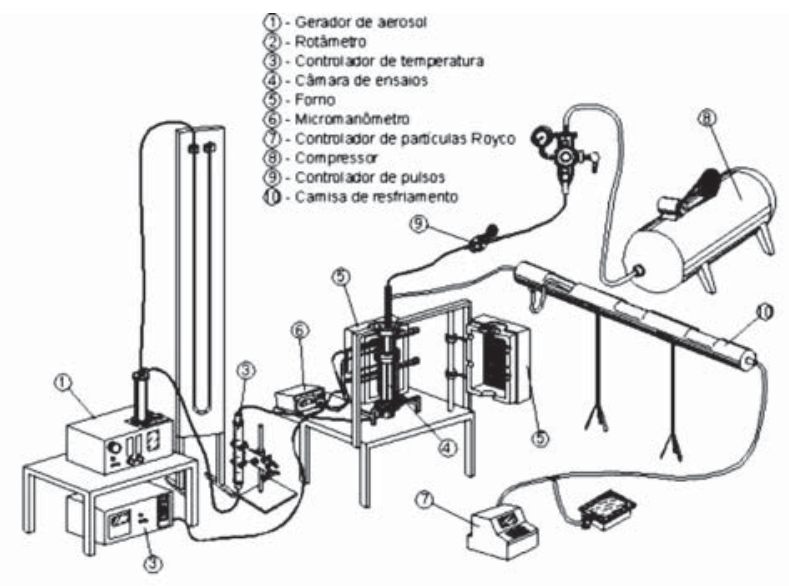

Figura 1: Sistema experimental utilizado. [Figure 1: General view of the experimental rig.]
A velocidade superficial do gás foi obtida por meio da razão entre a vazão volumétrica de ar, que foi medida em rotâmetro, e a área da seção transversal ortogonal ao escoamento. A velocidade foi corrigida para a temperatura de operação.

A queda de pressão foi medida por meio de manômetros, com tomadas de pressão imediatamente antes e após a amostra.

A filtração foi realizada verticalmente em sentido ascendente. A limpeza do filtro foi feita com ar fornecido de um compressor, por meio de um pulso de ar em sentido contrário ao da filtração (descendente).

As partículas na entrada e na saída do filtro foram quantificadas por meio do contador de partículas Hiac/Royco Modelo 5230, que conta o número de partículas em dez faixas de tamanho entre 0,5 e $20 \mu \mathrm{m}$. Por meio da densidade do material particulado e o número de partículas na entrada e na saída do filtro, foi possível obter as massas de partículas $\left(\mathrm{M}_{\mathrm{e}} \mathrm{e}\right.$ $M_{s}$ ), por faixa de tamanho.

O material particulado utilizado nos testes experimentais foi um concentrado fosfático de Patos de Minas, com densidade de $2970 \mathrm{~kg} / \mathrm{m}^{3}$.

Os ensaios foram realizados em duas etapas, a fim de obter número total de partículas que saía do filtro (Partículas na Saída do Filtro) e número total de partículas que entrava no filtro (Partículas na Entrada do Filtro), por faixa de tamanho.

Para a realização dos ensaios de eficiência de coleta foi utilizado o equipamento descrito.

\section{Obtenção do número de partículas na saída do filtro}

Inicialmente, o filtro era inserido no porta-amostra e o forno fechado. $O$ filtro utilizado nos experimentos era virgem. Eram anotadas a temperatura e pressão ambiente para a correção dos parâmetros aerodinâmicos (vazão, densidade e viscosidade do gás). A linha de ar comprimido era aberta, o gerador de aerossol era ligado para a estabilização da concentração de particulados e fixava-se a vazão desejada no rotâmetro. Após $10 \mathrm{~min}$, iniciava-se o experimento, acionando-se o cronômetro (para a contagem do tempo) e inserindo o aerossol no sistema de filtração. A cada minuto era anotadas a queda de pressão e as temperaturas acima e abaixo do filtro e conectava-se a mangueira do Royco à saída desse, para a contagem das partículas. Esse procedimento era repetido a cada 4 min e o ensaio encerrava-se aos 22 min. Uma vez que a queda de pressão causava uma diminuição na vazão, eram feitos ajustes periódicos no rotâmetro, para a manutenção da velocidade superficial do gás constante. Encerrado o experimento realizado à temperatura ambiente trocava-se o filtro e o controlador de temperatura era ligado para o aquecimento do aerossol. Esperava-se até atingir os $300^{\circ} \mathrm{C}$ e iniciava-se o experimento novamente, realizado da mesma forma que o ensaio realizado à temperatura ambiente. Entretanto, nesse caso, o ar que saía do filtro passava por uma camisa de resfriamento antes de atingir o Royco, pois esse contador suportava temperaturas até $50{ }^{\circ} \mathrm{C}$. Ao terminar o ensaio a $300^{\circ} \mathrm{C}$, trocava-se o filtro novamente e ajustava o controlador de temperatura para que se atingisse $700{ }^{\circ} \mathrm{C}$ e realizava-se o experimento da mesma maneira do realizado à $300^{\circ} \mathrm{C}$. 
Obtenção do número de partículas na entrada do filtro

Nesse caso, o forno era fechado sem a colocação do filtro no porta-amostra. Eram feitas 10 contagens do número de partículas para cada faixa granulométrica para permitir a estabilização dos valores. $\mathrm{O}$ valor assumido como o número de partículas que entrava no filtro por faixa foi uma média dos valores obtidos estabilizados.

\section{Cálculo da eficiência de coleta global}

Como a eficiência de coleta fracionária é a eficiência para cada faixa de diâmetro de partícula do material particulado, a qual é obtida mediante uma análise de distribuição de partícula.

A eficiência de coleta experimental, por faixa granulométrica $\left(\mathrm{E}_{\mathrm{i}}\right)$, foi determinada pela Equação A:

$$
E_{i}=\frac{N_{e, i}-N_{s, i}}{N_{e, i}} \cdot 100 \%
$$

onde, $\mathbf{N}_{\mathrm{e}, \mathrm{i}}$ é número de partículas com diâmetro dpi na entrada do filtro; $\mathbf{N}_{\mathrm{s}, \mathrm{i}}$ é número de partículas com diâmetro dpi na saída do filtro e i $\mathbf{i}^{\mathrm{s}}$ é a faixa analisada.

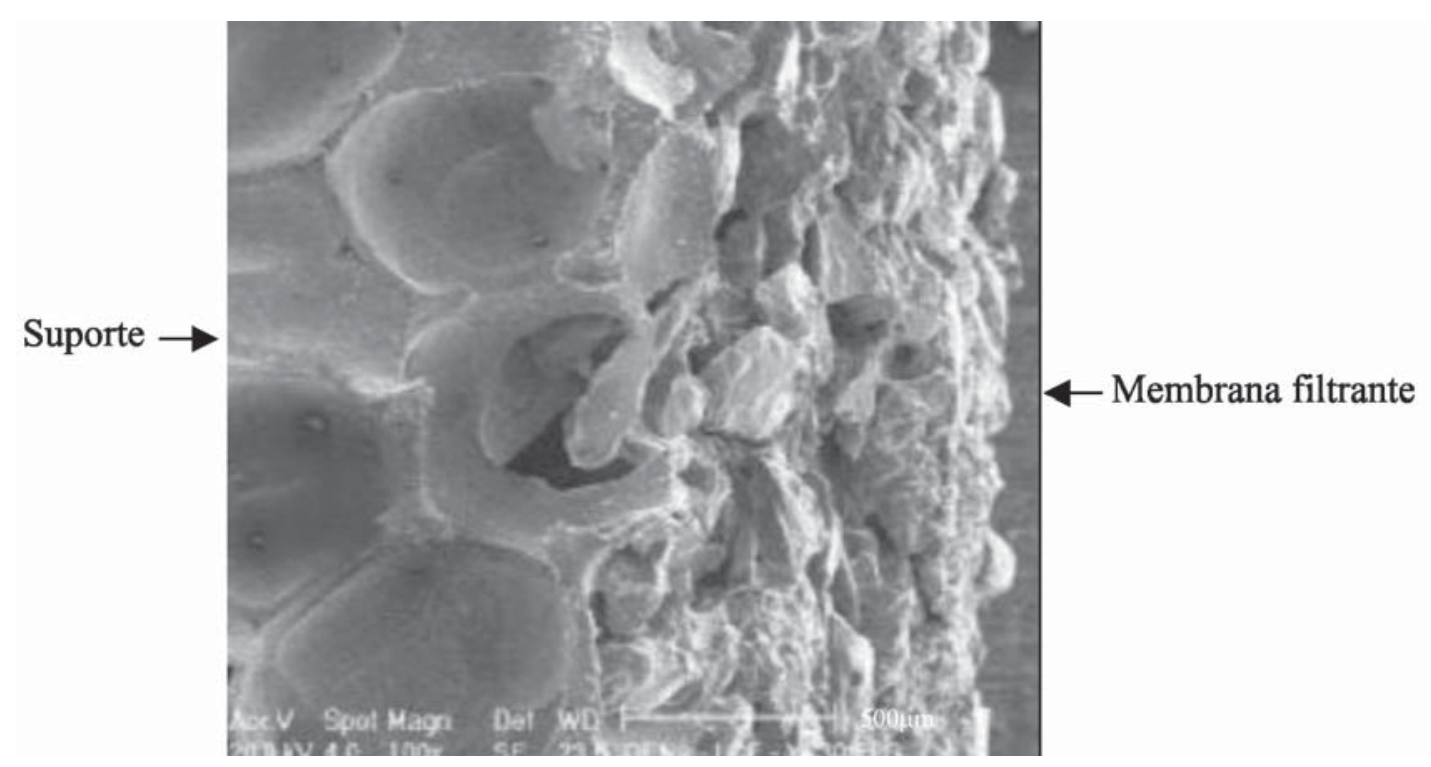

Figura 2: Micrografia obtida em microscópio eletrônico de varredura da interface da membrana filtrante com o suporte de 45 ppi. [Figure 2: Scanning electro microscope micrograph of the interface between the filtering membrane and the support of 45 ppi.]

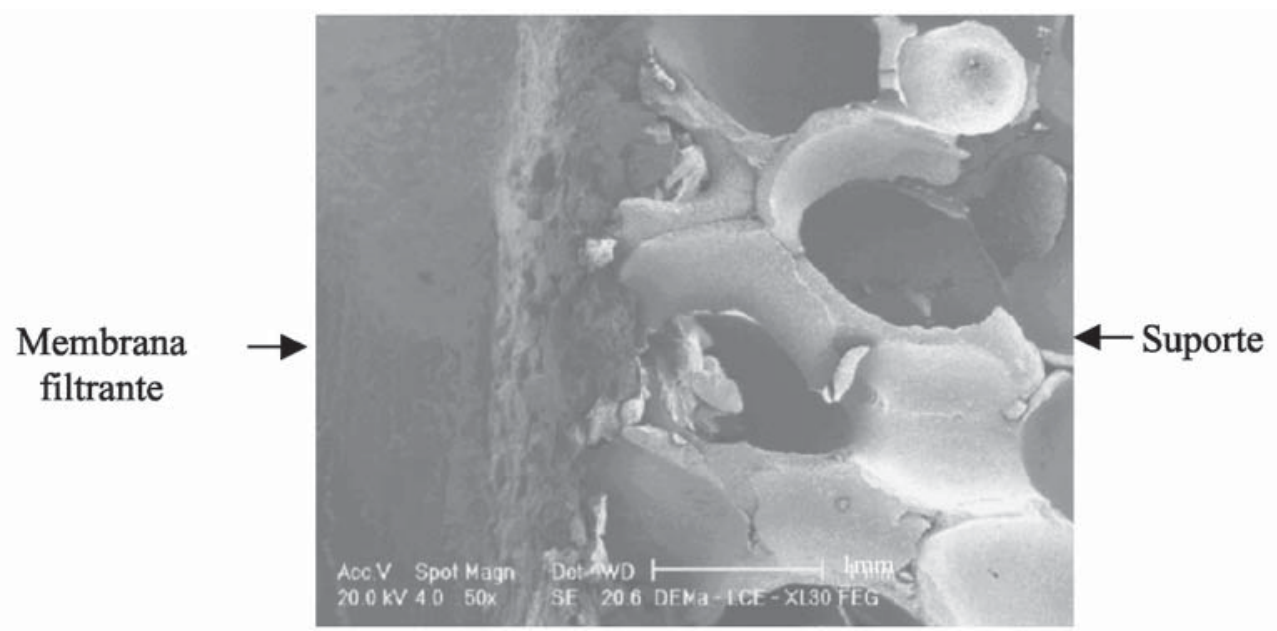

Figura 3: Micrografia obtida em microscópio eletrônico de varredura da interface da membrana filtrante com o suporte de 75 ppi. [Figure 3: Scanning electron microscope micrograph of the interface between the filtering membrane and the support of 75 ppi.] 

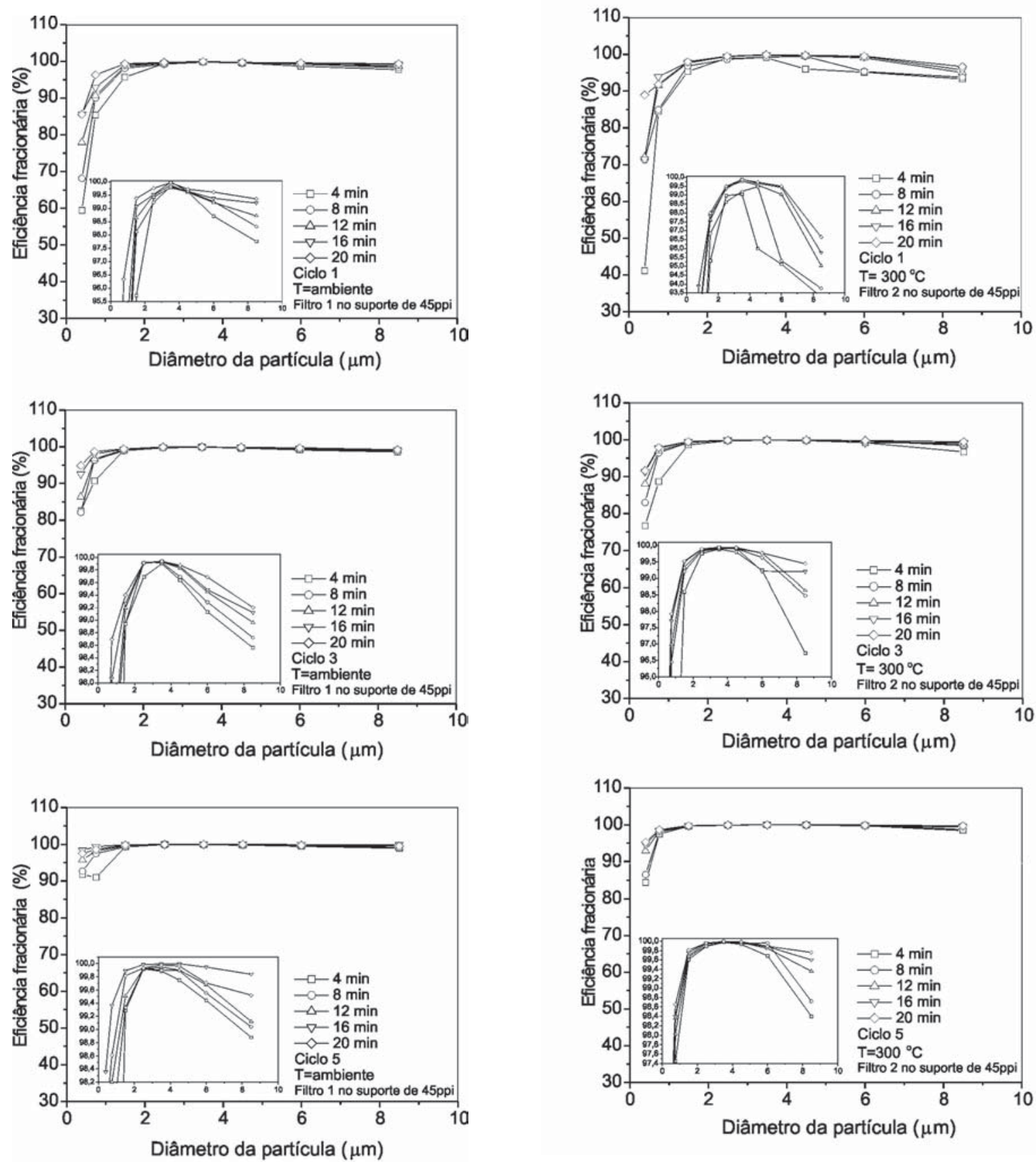

Figura 4: Eficiência de coleta em função do diâmetro de partícula do material particulado na temperatura ambiente para o filtro 1 no suporte de 45 ppi.

[Figure 4: Collection efficiency as a function of particle diameter at ambient temperature for filter 1, support of 45 ppi.]

\section{Ensaios}

Para a realização desse trabalho foram realizados ensaios utilizando o filtro no suporte de 45 ppi e 75 ppi, três níveis de temperaturas (ambiente, 300 e $700{ }^{\circ} \mathrm{C}$ ), velocidade superficial de filtração de $10 \mathrm{~cm} / \mathrm{s}$ e tempo de filtração variando de 4 a $20 \mathrm{~min}$.

Figura 5: Eficiência de coleta fracionária em função do diâmetro de partícula do material particulado na temperatura de $300{ }^{\circ} \mathrm{C}$ para o filtro 2 no suporte de 45 ppi.

[Figure 5: Collection efficiency as a function of particle diameter at $300^{\circ} \mathrm{C}$ for filter 2, support of 45 ppi.]

\section{RESULTADOS E DISCUSSÃO}

As Figs. 2 e 3 mostram, em detalhes, as microfotografias da interface entre a camada filtrante e o suporte para os filtros com suportes de 45 e 75 ppi respectivamente, obtidas pelo 

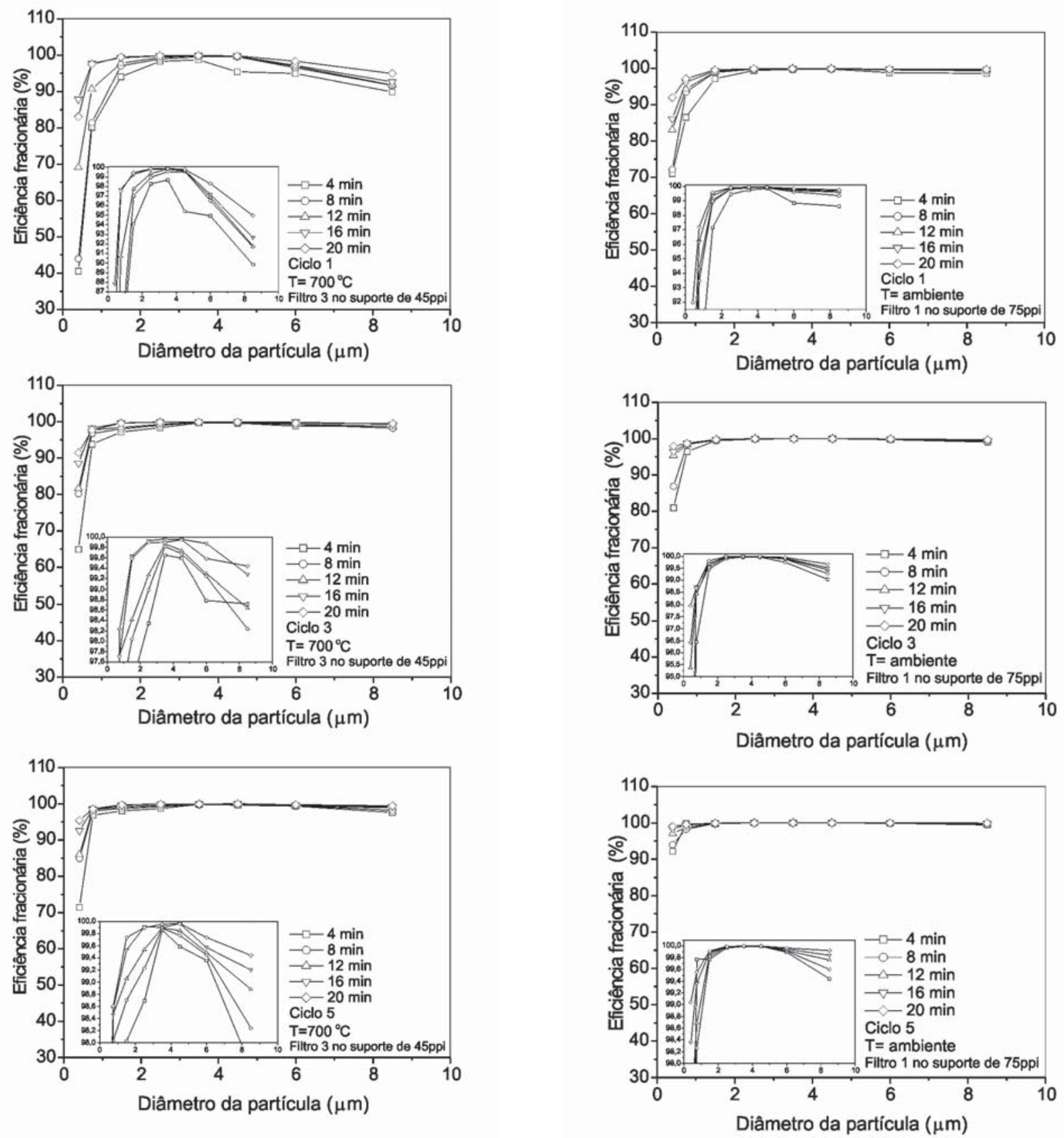

Figura 6: Eficiência de coleta fracionária em função do diâmetro de partícula do material particulado na temperatura de $700{ }^{\circ} \mathrm{C}$ para o filtro 3 no suporte de 45 ppi.

[Figure 6: Collection efficiency as a function of particle diameter at $700{ }^{\circ} \mathrm{C}$ for filter 3 , support of 45 ppi.]

microscópio eletrônico de varredura Philips XL30 FEG, com ampliação de 50 e 100 vezes, respectivamente.

Por meio das Figs. 2 e 3, pode-se visualizar a interação das partículas de alumina eletrofundida com a estrutura porosa de ambos os suportes, onde pode-se constatar, que a membrana filtrante tem uma estrutura bastante complexa, onde se nota

Figura 7: Eficiência de coleta fracionária em função do diâmetro de partícula do material particulado na temperatura ambiente para o filtro 1 no suporte de 75 ppi.

[Figure 7: Collection efficiency as a function of particle diameter at ambient temperature for filter 1, support of 75 ppi.]

uma camada uniforme, constituída de alumina eletrofundida, e de uma mista, onde a massa da membrana penetrou nos primeiros poros do suporte reticulado cerâmico.

Toda essa morfologia teve conseqüências diretas no desempenho do filtro, conforme discutido adiante na eficiência de coleta fracionária. 

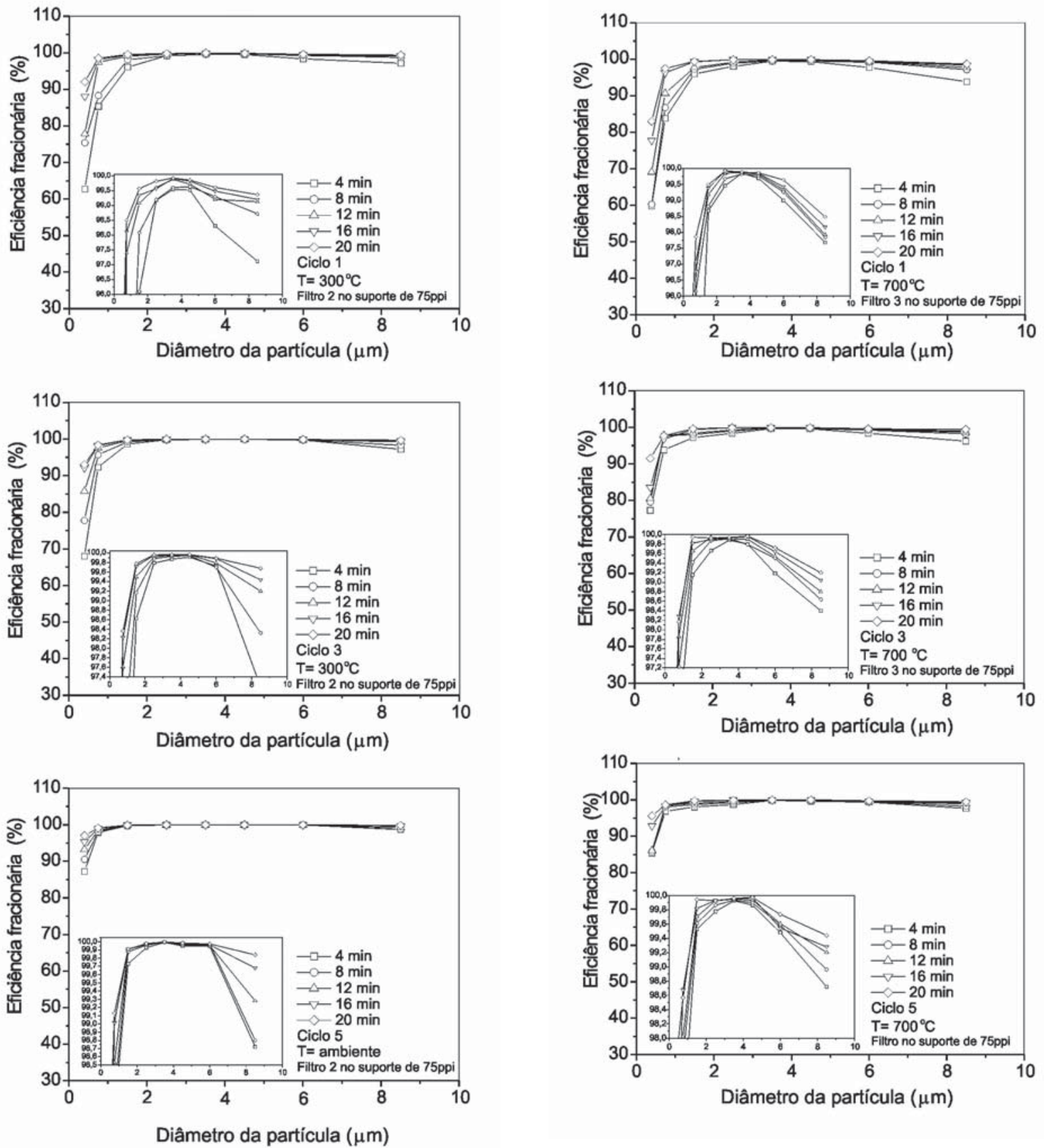

Figura 8: Eficiência de coleta fracionária em função do diâmetro de partícula do material particulado na temperatura de $300{ }^{\circ} \mathrm{C}$ para o filtro 2 no suporte de 75 ppi.

[Figure 8: Collection efficiency as a function of particle diameter at $300{ }^{\circ} \mathrm{C}$ for filter 2, support of 75 ppi.]

Nas Figs. de 4 a 9 são ilustrados os dados de eficiência de coleta em função do diâmetro do material particulado nas três temperaturas para os tempos e ciclos de filtração estudados, para os filtros nos suportes de 45 e 75 ppi.

Em cada figura encontram-se detalhes ampliados dos dados na faixa de 98 a $100 \%$, para melhor visualização do

Figura 9: Eficiência de coleta fracionária em função do diâmetro de partícula do material particulado na temperatura de $700{ }^{\circ} \mathrm{C}$ para o filtro 3 no suporte de 75 ppi.

[Figure 9: Collection efficiency as a function of particle diameter at $700{ }^{\circ} \mathrm{C}$ for filter 3 , support of 75 ppi.]

comportamento das partículas de diâmetro acima de $2 \mu \mathrm{m}$.

Verifica-se que, em todos os testes efetuados, as eficiências de coleta foram bastante altas, próximas a $100 \%$, o que credencia o filtro cerâmico de dupla camada como alternativa muito promissora para a limpeza de gases a altas temperaturas.

Por meio das Figs. 4 a 6 observa-se que a eficiência de 
coleta fracionária aumenta com o crescimento do diâmetro da partícula, conforme o esperado, uma vez que as partículas maiores têm uma maior inércia. Foi observado que o aumento da eficiência de coleta foi até o diâmetro de partícula com tamanho de 3,5 $\mu \mathrm{m}$, mostrando a predominância do mecanismo de coleta inercial, enquanto que para um diâmetro de partícula maior que 3,5 $\mu \mathrm{m}$ observa-se um decréscimo na eficiência de coleta. Estudos realizados em 1996, mostraram que para a região de alta inércia da partícula ocorreu decréscimo da eficiência do filtro com o aumento do número de Stokes, contrário ao previsto por considerações teóricas [15]. Este fenômeno foi atribuído ao "ricochete" da partícula na superfície coletora [14]. Este fenômeno foi observado para todas as temperaturas estudadas.

O mesmo foi observado nas Figs. 7 a 9 (filtros com suporte de 75 ppi), só que o aumento da eficiência de coleta ocorreu até o diâmetro de partícula de $4,5 \mu \mathrm{m}$, e acima deste diâmetro uma diminuição da eficiência de coleta, acontecendo também o "ricochete" das partículas nos coletores.

Observa-se também um aumento nas eficiências de coleta ao longo do tempo de filtração e ciclos estudados. Tal comportamento é característico de filtros tipo barreira, pois, após a retenção, as partículas coletadas contribuem para a captura de novas partículas.

Por meio das Figs. 4 a 9, nota-se que as eficiências de coleta são maiores para os filtros com suporte de 75 ppi do que as obtidas para os filtros com suporte de 45 ppi em todas as temperaturas estudadas. Note-se que o diâmetro do poro do suporte de 75 ppi vale $0,266 \mathrm{~mm}$, enquanto que o do suporte de 45 ppi é de $\quad 0,546 \mathrm{~mm}$. Isto mostra que a camada suporte, embora altamente porosa, também contribui para a filtração: o suporte com menores poros apresentou uma melhor barreira às partículas, aumentando a eficiência de coleta.

A observação mais significativa das figuras diz respeito ao efeito da temperatura: a eficiência de coleta global diminui com o aumento da temperatura.

As razões para tal comportamento são diversas. Pode-se afirmar que o aumento de temperatura provoca alterações nas propriedades do gás (diminuição da densidade e aumento da viscosidade) que alteram a capacidade de remoção do filtro. Por outro lado, o aumento da temperatura causa também mudança estrutural no meio poroso devido à expansão térmica que. Essa alteração, embora pequena em magnitude, pode ter efeitos consideráveis na capacidade de remoção do filtro.

É interessante frisar que, embora uma diminuição na eficiência aconteça com o aumento da temperatura, os níveis de remoção permanecem bastante altos, e não comprometem o desempenho do filtro.

As Figs. 4 a 9 também mostram que a eficiência de coleta aumenta à medida que se aumenta o número de ciclos de filtração. Tal resultado indica que o filtro acondiciona-se, isto é, atinge um equilíbrio do material retido no meio filtrante e que não é removido no processo de limpeza.

\section{CONCLUSÕES}

Com base nos resultados apresentados, conclui-se que os filtros utilizados apresentaram características que viabilizam a sua utilização na filtração industrial de gases quentes: altas eficiências de coleta para a faixa operacional estudada. $\mathrm{O}$ material utilizado como suporte, embora altamente poroso, influenciou na eficiência de coleta dos filtros.

O fenômeno de rebatimento das partículas, característicos para as regiões onde predomina o mecanismo inercial, foi bem evidenciado experimentalmente em todas as temperaturas e filtros aqui estudados.

A eficiência de coleta aumenta com o decorrer do tempo e dos ciclos para todas as faixas de diâmetros de partícula e temperaturas estudadas mostrando o processo de acondicionamento do filtro.

A eficiência de coleta fracionária aumenta com o decorrer do tempo e dos ciclos para todas as faixas de diâmetros de partícula e temperaturas estudadas mostrando o processo de acondicionamento do filtro.

\section{AGRADECIMENTOS}

Os autores agradecem à FAPESP, ao CNPq e ao PRONEXFINEP pelo apoio dado para a realização desta pesquisa.

\section{REFERÊNCIAS}

[1] L. Bergmann, in: Gas Cleaning at High Temperature, Eds.: Clift and Seville, Blackie A\&P, UK (1993) p. 294-306.

[2] W. Peukert, F. Loffler, Powder Tech. 68 (1991) 263-270.

[3] J. P. K. Seville, W. Cheung, R. Clift, Filtration \& Separation (1989) 187-190.

[4] J. P. K. Seville, S. Ivatt, G. K. Burnard, in: High Temperature Gas Cleaning, Ed. Schmidt (1996) p. 3-25.

[5] J. F. Zievers, P. M. Eggerstedt, E. C. Zievers, Am. Ceram. Soc. Bull. 70, 1 (1991) 108-111.

[6] R. R. Judkins, D. P. Stinton, J. H. Devan, J. Eng. for Gas Turbines and Power - Trans. ASME 118, 3 (1996) 500-506.

[7] R. R. Judkins, D. P. Stinton, R. G. Smith, E. M. Fischer, J. H. Eaton, B. L. Weaver, J. L. Kahnke, D. J. Pysher, J. Eng. for Gas Turbines and Power - Trans. ASME 118, 3 (1996) 495499.

[8] T. E Lippert, R. A. Newby , M. A. Alvin , D. M. Bachovchin, G. J. Bruck, E. E. Smeltzer, J. Eng. for Gas Turbines and Power - Trans. ASME 115, 3 (1993) 658-664.

[9] I. Owen, N. Syred, G. P. Reed, J. Dynamic Systems 105 (1983) 185-191.

[10] M. D. M. Innocentini, Tese de Doutorado, DEQ-UFSCar (1997).

[11] N. L. Freitas, V. R. Salvini, M. D. M. Innocentini, V. C. Pandolfelli, J. R. Coury, Anais do XIX Cong. Bras. Eng. Quím., Natal, RN (2002).

[12] M. G. Maniero, N. L. Freitas, J. R. Coury, V. R. Salvini, V. C. Pandolfelli, Anais do XXX Cong. Bras. Sist. Part., S. Carlos, SP (2002).

[13] M. G. Maniero, Dissertação de Mestrado, DEQ-UFSCar (2003).

[14] N. L. Freitas, Tese de Doutorado, DEQ-UFSCar (2003).

[15] S. Cavenati, Dissertação de Mestrado, DEQ-UFSCar (1996).

(Rec. 28/06/04, Ac. 15/10/04) 